\title{
Warning over link between frailty and oral health
}

An oral health charity has highlighted a link found in a recent study between oral health and other problems later in life.

A study ${ }^{1}$ published recently in the Gerondontology journal found that poor oral health appeared to be independently associated with problems in later life.

The Australian research found that older people with muscular weakness, sudden weight loss or impaired mobility were substantially more prone to issues with their oral health.

The investigation linked frailty to a number of consequences for oral health including the ability to bite and chew food, as well as sensitivity to hot and cold foods and drinks.

The study was carried out by a team of researchers from the Monash Ageing Research Centre (MONARC), Monash Health and Monash University, Melbourne, Australia.

They examined 168 geriatric inpatients aged over 65 years over a six-month period and used previously validated tools to assess peoples' oral health, nutrition and frailty, while also using other data on demographics, co-morbidities, level of education and smoking/alcohol history.

Results showed that frail adults were more likely to feel self-conscious about their teeth, gums or dentures. They were also unhappy with how their teeth looked and frail adults tended to access dental care less often.

Charity, the Oral Health Foundation, said the study underlined a growing problem, given that in the UK, more than five million people aged over 65 experience significant health problems.

Foundation Chief Executive, Dr Nigel Carter said: 'In the UK, people are living longer than ever before. This will increase the amount of poor health, frailty and disability. In turn, it will create a series of challenges for how we care for the population's oral health.

'The first problems to occur are often because of a loss of dexterity. Limited mobility, no matter how small, can have an extremely large effect on our ability to care for our own health. In terms of oral health, this means effective toothbrushing becomes much harder. Balanced nutrition also becomes more difficult. This often leads to more frequent sugar consumption.

'Those with health problems are also more likely to be on medication. This makes unpleasant conditions like dry mouth far more common.'

The charity called on the government to take action and improve the provision of oral healthcare for older people.

'The availability of dentists needs to be urgently addressed,' added Dr Carter.

'There are also major barriers with transporting elderly people to the dentist while financial difficulties often become more common. Worryingly, there is also a poor knowledge and a lack of awareness of oral health amongst carers.

'All of these factors create an urgent need to move towards a more effective system for oral healthcare of our elderly'

\section{References}

1. Shwe PS, Ward S A, Thein P M, Junckerstorff R Frailty, oral health and nutrition in geriatrics inpatients: A cross-sectional study. Gerodontology 2019; DOI: 10.1111/ger.12397.

\section{Western Isles get first new dental practice in 30 years}

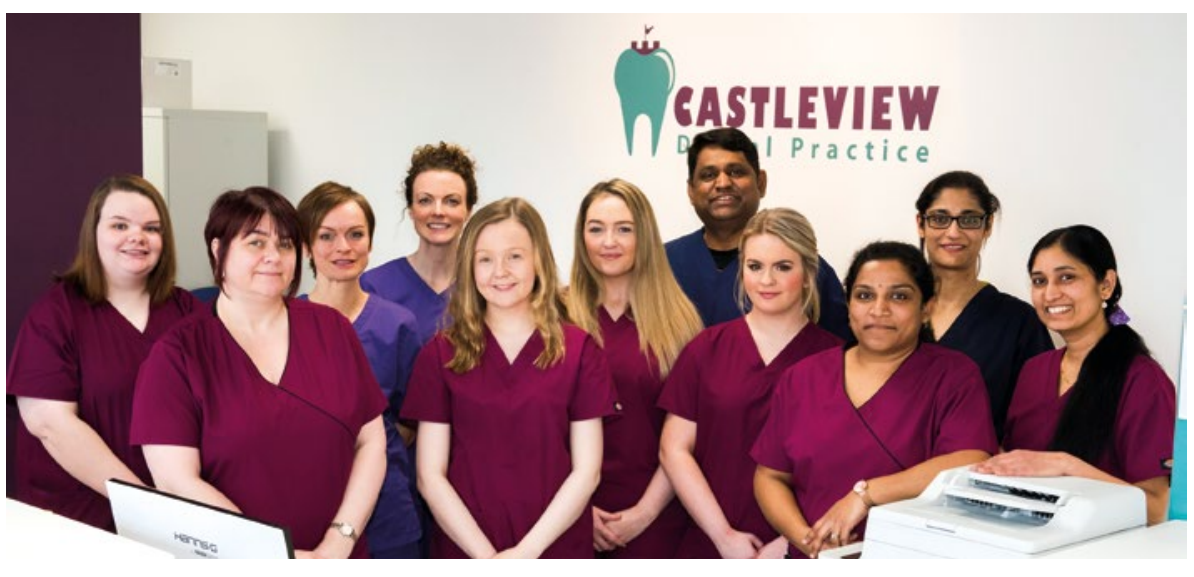

The first new dental practice to be established in the Western Isles in Scotland in more than 30 years has opened its doors in the Isle of Lewis town of Stornoway.

The Castleview Practice has opened under the direction of owner, dentist Dr Sridhar Kalvakuntla.

It will offer NHS treatment to patients, alongside private treatments provided by two dentists, a dental therapist, a dental hygienist, six dental nurses and two receptionists.

Dr Kalvakuntla comes from his previous role working as a dentist with NHS Western Isles Dental Centre in Stornoway since 2016 and has worked for health trusts in England as well as both NHS Dumfries and NHS Grampian in Scotland.
Dr Kalvakuntla said: 'Opening Castleview is a big responsibility but it is also exciting. At Castleview our main priority is to keep our patients pain free. We understand the majority of patients can be anxious about dental treatment, and we put all efforts in to providing a stress-free environment in our new practice.

'We will be encouraging preventative care for our patients through regular attendance (every six months), and aim to attend emergencies within 24 hours with daily emergency appointments available. We also have a good referral system in place should patients need specialist care.'

Colin Robertson, NHS Western Isles Chief Dental Officer, said: 'Opening Castleview Dental Practice is a huge act of confidence on Sridhar's part.

'His new practice adds choice, and will reduce waiting times in Lewis. His new premises are exceptional and show the level of commitment he has made to this project.' 